\title{
Hazardous waste landfill sites and congenital anomalies
}

\section{R M Harrison}

\section{Where do we go from here?}

T EUROHAZCON collaborative group reported a further stage of their research on connections between congenital anomalies and hazardous waste landfill sites in the November 2002 issue of Occupational and Environmental Medicine. ${ }^{1}$ An expert panel scoring method has been used to estimate the hazard potential of EUROHAZCON landfill sites and to investigate whether sites classified as posing a greater potential hazard are those with a greater risk of congenital anomaly among nearby, relative to distant residents.

Municipal and hazardous wastes are an inevitable byproduct of developed societies. While the public are content to generate domestic waste in ever larger quantities, they appear very reluctant to face up to the realities of disposal, especially when proposals relate to their own neighbourhood. The greatest adverse reactions seem to centre on incineration, which is nowadays subject to very strict engineering and operational controls such that the health consequences of an incinerator for local populations should be extremely small. In opposing incinerators, environmental pressure groups generally stress the desirability of greater recycling and there are few that would deny that more could be done on this front. However, there is a limit to which components of waste can usefully be recycled, and not all recycled materials are of the same quality as those produced from virgin feedstocks. ${ }^{2}$ There are also very real concerns over health impacts of recycling plants for workers and local residents, and over the composting plants which can deal with the putrescible materials within domestic waste. The last resort disposal option is landfill, and while the regulatory regime is now discouraging landfill, there will always be a role for it for materials which are not suitable for recycling, composting, or incinerating, and particularly for hazardous wastes, including the air pollution control residues from incinerators which contain the toxic materials trapped to avoid emission to the atmosphere

Over recent years, UK practice has been towards co-disposal of hazardous waste and municipal waste in common landfills. In future, because of European regulations, this will not be possible. However, there is a large number of current or past co-disposal landfill sites across the country, and according to Elliott and colleagues, ${ }^{3} 80 \%$ of the population lives within $2 \mathrm{~km}$ of a current or closed landfill site. While the majority of these sites have probably not accepted hazardous waste, records for the older sites are poor or non-existent and it is hard to differentiate between those which have and have not been used for hazardous waste disposal. Potentially, therefore, a large proportion of the UK population is at risk of exposure to hazardous waste or its byproducts. However, when excluding landfill sites that closed before 1982, Elliott and colleagues $^{3}$ found only a small excess risk of congenital anomalies and low and very low birth weights in populations living near landfill sites. Findings for special (hazardous) waste sites did not differ systematically from those for nonspecial sites. In contrast to these results, however, the EUROHAZCON study showed a 33\% increase in risk of non-chromosomal anomalies near hazardous waste landfill sites, ${ }^{4}$ and in a subsequent study, ${ }^{5}$ reported a similar increase in risk of chromosomal anomalies.

" $80 \%$ of the population lives within $2 \mathrm{~km}$ of a landfill site"

The EUROHAZCON studies are based on a geographic analysis in which residence within $0-3 \mathrm{~km}$ of a landfill is taken as a proxy of exposure, with the population in the 3-7 km band taken as the reference population. This is inevitably a very crude means of differentiating the notionally exposed from the unexposed population, especially since the pathways of exposure are uncertain and there is a lack of measurements indicating exposure to any particular toxic substance. In order to move the subject forward, the EUROHAZCON collaborative group has engaged a panel of experts to rank 14 study areas around 20 landfill sites in terms of hazard in three categories-overall, water, and airbased on readily available documented data on site characteristics. While the agreement between the experts on the relative hazard ranking of the sites was relatively good, the results show little evidence of a relationship between risk of congenital anomaly in proximate relative to distant zones and the hazard potential of the landfill sites as classified by the expert panel. It is unclear whether the lack of the relationship is because of the absence of a causal relationship or is caused by a failure of the expert panel to classify sites appropriately.

A very wide range of waste materials goes into landfills, especially those which accept hazardous waste. Undoubtedly, the list of substances includes some of the many known to be teratogenic in experimental animals. Modern landfills are designed to provide a high level of containment for leachate waters, and landfill gas is collected and generally used in energy conversion. Where these measures are ineffective, however, or in the case of less well designed older landfills, it is plausible that atmospheric transport of toxic materials within landfill gas may lead to direct exposure of local residents to volatile materials. Additionally, leachate water may act as a vector for transferring materials from the landfill to points where they could be abstracted for water supply. This is relatively unlikely as an exposure pathway in the UK because of the very comprehensive monitoring of the quality of water used for public supply and the rather small numbers of less adequately monitored private supplies. It is, however, feasible that substances transferred via groundwater may subsequently enter the atmosphere either as vapour or attached to soil particles, thereby leading to public exposure. Through comprehensive site investigations, it is perfectly possible to monitor the occurrence of such processes and to establish levels of public exposure should this occur. It is worth pointing out at this juncture that incinerators, much feared by the public as potential sources of pollution, offer an inherently far better contained and controlled source of emissions than any realistic landfill.

"The greatest weakness is in
differentiating exposed from
unexposed populations"

With such a large proportion of the population having a potential exposure to landfill, it is important in public health terms to resolve whether any adverse effects occur, and perhaps equally importantly, to establish what chemical agent or agents are responsible. The paper by Vrijheid and colleagues clearly shows the limitations of the expert panel approach. We therefore need to find better ways of investigating 
these problems. Currently, the greatest weakness is in differentiating exposed from unexposed populations. To improve on this, differentiation will require some detailed environmental investigations of landfills in the category of higher risk as shown by the epidemiology. The questions which will need to be addressed relate to the points of release and the substances released to the atmosphere, and the pathways of groundwater movement and whether these lead to contamination of drinking water supplies or to release of volatile chemicals to the atmosphere. The results of such an investigation could lead to either measurement or modelling of exposures, which in combination with spatial epidemiology, might not only resolve the still open question as to whether there is in fact a causal relationship between hazardous waste landfills and congenital anomalies (and other adverse health outcomes), but also lead to identification of the agents responsible.

Occup Environ Med 2003;60:79-80

\section{Author's affiliation}

R M Harrison, Division of Environmental Health and Risk Management, University of

Birmingham, UK

Correspondence to: Prof. R M Harrison, Division of Environmental Health and Risk Management, University of Birmingham, Edgbaston,

Birmingham B15 2T, UK ;

r.m.harrison.ipe@bham.ac.uk

\section{REFERENCES}

1 Vrijheid M, Dolk H, Armstrong B, et al. Hazard potential ranking of hazardous waste landfill sites and risk of congenital anomalies. Occup Environ Med 2002;59:768-76.

2 Clift R. Clean technology and industrial ecology. In: Harrison RM, ed. Pollution: causes, effects and control, 4th edn. Cambridge: Royal Society of Chemistry, 2001:411-44.

3 Elliott P, Briggs D, Morris S, et al. Risk of adverse birth outcomes in populations living near landfill sites. BM 2001;323:363-8.

4 Dolk H, Vrijheid M, Armstrong B, et al. Risk of congenital anomalies near hazardous-waste landfill sites in Europe: the EUROHAZCON study. Lancet 1998:352:423-7.

5 Vriiheid M, Dolk H, Armstrong B, et al. Chromosomal congenital anomalies and residence near hazardous waste landfill sites. Lancet 2002;359:320-2.

Answers to multiple choice questions on How much does the environment contribute to cancer? by L Rushton, on pages 150-156

(1) (a) true; (b) false; (c) true; (d) false; (e) false

(2) (a) true; (b) true; (c) false; (d) true; (e) false

(3) (a) true; (b) false; (c) true; (d) false; (e) false

(4) (a) true; (b) false; (c) true; (d) true; (e) false

(5) (a) true; (b) false; (c) true; (d) false; (e) true 